\title{
Using Problem-Based Learning to Explore Qualitative Research
}

Roisin Donnelly

Technological University Dublin, roisin.donnelly@tudublin.ie

Follow this and additional works at: https://arrow.tudublin.ie/ltcart

Part of the Teacher Education and Professional Development Commons

\section{Recommended Citation}

Donnelly, R.: Using Problem-Based Learning to Explore Qualitative Research. European Research Journal, Vol. 2, 2, 2003, pp. 309-321.

This Article is brought to you for free and open access by the Learning Teaching \& Assessment at ARROW@TU Dublin. It has been accepted for inclusion in Articles by an authorized administrator of ARROW@TU Dublin. For more information, please contact arrow.admin@tudublin.ie, aisling.coyne@tudublin.ie, gerard.connolly@tudublin.ie.

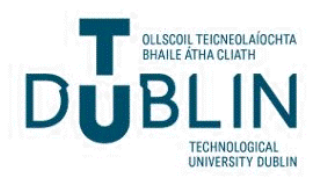




\title{
Using Problem-based Learning to Explore Qualitative Research
}

\author{
ROISIN DONNELLY \\ Dublin Institute of Technology, Republic of Ireland
}

\begin{abstract}
The aim of this article is to discuss an approach to deliver a component on qualitative research on a research methods module in a postgraduate diploma in third level learning and teaching using problem-based learning (PBL). The Diploma in Third Level Learning and Teaching is on offer to a variety of academic staff (lecturers) in higher education at a higher education institute in Ireland, hereafter referred to as participants. The 10-week Research Methods module is one of eight offered on the Postgraduate Diploma, all designed and delivered using the pedagogic strategy of PBL. The entire Postgraduate Diploma is voluntary, and only lecturers who are keen to implement novel pedagogical approaches in their own subject disciplines apply for a place on the modules. However, the key to the participants' success is by using the principles of PBL to share and discuss valuable information with their colleagues in a variety of other disciplines. The opportunity is being given to enhance group learning in a real-life multidisciplinary learning environment. The objective of this module was to explore qualitative research methods and their distinctive value as an educational research approach. The learning issues established in the PBL group focused on the relationship between the actual real-life authentic problem, the theoretical underpinning and epistemology associated with a qualitative research approach.
\end{abstract}

\section{Introduction}

This article discusses an approach to deliver a component on qualitative research on a research methods module in a postgraduate diploma in third level learning and teaching using problem-based learning (PBL). The Diploma in Third Level Learning and Teaching is on offer to a variety of academic staff (lecturers) in higher education at a higher education institute in Ireland, hereafter referred to as participants. The 10-week Research Methods module is one of eight offered on the Postgraduate Diploma, all designed and delivered using the pedagogic strategy of PBL. The entire Postgraduate Diploma is 
voluntary, and only lecturers who are keen to implement novel pedagogical approaches in their own subject disciplines apply for a place on the modules.

The aim of the Research Methods module is to provide a broad understanding of the research methodologies used in research in higher education today, and to present at postgraduate level, the theory for applying research methods and skills to all aspects of learning and teaching. This module also aims to prepare participants for planning a research proposal at Master's dissertation level.

In this module, PBL has been used to deliver the material on research methods in higher education, with the learning being centred on a real-life problem. The participants were aware that PBL is based on this problem, which has to engage students' interest, compel them to take it on as their responsibility, support the development and application of problem-solving and conceptual skills and stimulate self-directed learning into areas of study relevant to the curriculum (Barrows, 1999). All this takes place using a collaborative PBL process and is supported with tutor face-to-face and online facilitation sessions, using WebCT (online learning environment). As the PBL tutor in this group of eight lecturers, I was aware of the variety of discussions and literature reviewed on qualitative research which emerged from facilitating the PBL tutorial process on a particular problem.

The question can be asked why use a PBL approach for this, rather than continue allowing participants to research in a traditional learning environment? Quite simply, the main idea is to provide them with a taste of what is possible in a group environment for research. Therefore, the role of PBL is for the motivational benefits it provides. The participants are involved in active learning throughout, working with real-life research problems in their professional practice, and what they have to learn in their independent and collaborative study is seen as relevant and important to enhance this. Arguably, these factors are important for educational development to act to improve research in higher education today.

\section{Context of Problem-based Learning}

PBL has been used in a series of medical schools since the 1960s (McMaster, Maastricht, Harvard) and increasingly in professional schools (Berkeley, Stamford, Maastricht) and undergraduate institutions (Aalborg, University of Delaware, Maastricht). Students confront a complex problem before they receive all content information needed to solve the problem. In groups, they organise their previous knowledge and new ideas and attempt to define its nature DO YOU MEAN THE NATURE OF THE PROBLEM?. Students pose questions about what they do not understand, they design a plan to solve the problem, and they identify resources they need. Faculty members guide by asking questions.

In this module on Research Methods, PBL was used to build a disciplinary knowledge base on educational research methods and enhance the 
participants' critical thinking in the area. It was hoped to develop their problem-solving skills and improve teamwork and communication skills. Through a specially written problem on qualitative research, the tutor hoped to help the participants distinguish appropriate resources in the area.

\section{The Qualitative Problem}

The name and nature of the problem at the locus of the discussions on qualitative research being a credible mechanism to explore was 'Equality Analysis at European Level'. The PBL group had to consider themselves in the role of a team of researchers on a European project engaged to write a proposal for funding for the EU Equal Programme: Education and Training Strand (Ethnic Minorities). The project is about researching the barriers and supports in relation to the equal participation of students from ethnic minorities in higher education.

In this research proposal, the PBL group was to meet two criteria, inter alia, as follows:

- Justify the use of interviewing as a qualitative research method, in this context.

- Show a critical awareness of best European practice in the area of qualitative research.

As a team, they were expected to return to the next National Consortium Meeting scheduled for five weeks into the future to present the justification for using interviews as a qualitative research method in the EU Equal Programme strand context.

\section{Qualitative Learning Issues}

The group was aware that on encountering a new problem like this, they needed to rewrite it according to the contextual realities of one group member and clarify the key learning issues. The discussion began in the first week on the subject of many research funding agencies calling qualitative researchers 'journalists' or 'soft scientists' whose work is 'termed unscientific, or only exploratory, or entirely personal and full of bias' (Denzin \& Lincoln, 19942000 IN REFS, p. 4). Despite the 'rollercoaster ride' of popularity of quantitative research, qualitative researchers still largely feel themselves to be second-class citizens whose work typically evokes suspicion, where the 'gold-standard' is quantitative research (Silverman, 2001, p. 26). This has been the case for some time: 'in a bureaucratic-technological society, numbers talk' (Cicourel, 1964).

This issue was debated strongly by the eight participants in the PBL group, a majority of whom has undertaken research before, but whose research had been based on a quantitative approach. Other early quantitative researchers (Selltiz et al 1964, p. 435) also assumed that 'statistical analysis' is the bedrock of research. It was established that a similar view permeated 
through to a few decades later in Singleton et al (1988, p. 298), in which the authors approve of the use of field research 'when one knows relatively little about the subject under investigation'.

At this juncture, it was useful for the PBL group to specify what is meant by qualitative research. They looked at the available literature and reported back that Burgess (1982, p. 1) clarifies what he means by field research; a style of investigation that is also referred to as 'field-work', 'qualitative method', 'interpretive research', 'case study method' and 'ethnography'. The group found that the view has existed, and continues to exist, that qualitative research can only effectively be used to familiarise oneself with a setting before the serious sampling and counting begin: 'Damning by faint praise', as Silverman has described it (2001, p. 35). It was argued in the PBL group that these reservations do have some basis, given the fact that qualitative research is, by definition, stronger on long descriptive narratives than on statistical tables (Silverman 2001, p. 33).

Expanding this side of the argument, Hammersley \& Atkinson (1995, p. 1) admit that there is considerable variety in prescription and practice of qualitative research. They also state that there is a sharp distinction between the context of discovery and the context of justification. Qualitative research has come under criticism as lacking scientific rigour. It was sometimes dismissed as quite inappropriate to social science on the grounds that the data and findings it produces are 'subjective', mere idiosyncratic impressions of one or two cases that cannot provide a solid foundation for rigorous scientific analysis (Hammersley \& Atkinson, 1995, p. 6).

However this debate between proponents of empirical and of qualitative research can be traced to the opposition between the need for understanding and the desire to manipulate (Smeyers \& Verhesschen, 2001, p. 71). As the PBL group established, qualitative methods have lately enjoyed enhanced legitimacy and are increasingly used in academic and applied social research. Yet the field is marked by controversy about virtually every key tenet of qualitative inquiry, from matters of epistemology to purely practical matters of relations with research subjects. Not only is the practice of qualitative research hotly contested, consensus is lacking about the purpose of qualitative research and whether it has a distinctive role to play relative to other approaches to the study of social phenomena.

The underlying important aspect of the entire ongoing argument about the effectiveness of quantitative versus qualitative research is that the value of a research method should properly be gauged solely in relation to what it is trying to find out. The PBL group needed to explore the controversies and from that aim to establish the value of qualitative research for the context of the problem they were exploring.

Validity in interviewing was discussed by the group; Marshall \& Rossman (1999, p. 192) state that all research must respond to canons of quality, and in the case of the social science participants in the group, these were phrased as the following questions. First, how credible are the particular 
findings of a qualitative study? Second, how transferable and applicable are these findings to another setting or group of people; in this instance they are looking at the equal participation of students from ethnic minorities in higher education. Third, how can we be reasonably sure that the findings would be replicated if the study were conducted with the same participants in the same context? And fourth, how can we be sure that the findings reflect the participants and the inquiry itself rather than being a fabrication from the researcher's biases or prejudices?

Behar (1993) argues that the qualitative analyst ends up creating a metastory, editing and reshaping what was told, and turning it into a hybrid story, a 'false' document, where values, politics and theoretical commitments enter. It is true that investigators do not have direct access to another's experience: they deal with ambiguous representations of it - talk, text, interaction and interpretation. According to Peller (1987), it is not possible to be neutral and objective, to merely represent (as opposed to interpret) the world. Similarly, Riessman (1993, p. 8) states that qualitative researchers often seek to depict others' experiences but act as if representation is not a problem. As a qualitative researcher herself, she believes: 'we cannot give voice, but we do hear voices that we record and interpret. Representational decisions cannot be avoided; they enter at numerous points in the research process, and qualitative analysts must confront them.'

According to Gubrium \& Holstien IS THIS SPELLING CORRECT? (1997, p. 102), qualitative researchers inhabit the lived border between reality and representation'. They offer a practical device for the qualitative researcher. It is important to seek a middle ground to manage the tensions between reality and representation so that the many different, potentially conflicting models in qualitative research are given voice.

Connell et al (2001, p. 11) agree with Patton (1990, p. 64), who pointed out that, ultimately, the validity and reliability of qualitative data depends to a great extent on the methodological skill, sensitivity, and integrity of the researcher. The generation of useful and credible qualitative findings occurs through observation and interviewing, which requires significant discipline, knowledge, training, practice, creativity and hard work.

As Weber pointed out in the middle of the last century, all research is contaminated to some extent by the values of the researcher. Legend has it that the painter, Cézanne, said about Monet, 'He is only an eye - but what an eye!' Our own interpretation of this story is that both painters offered ways of looking at the world. Monet's way was different from Cézanne's way, but it was just as insightful and valuable (Strauss \& Corbin, 1998, p. 4).

The self-directed learning was an important aspect of the PBL group process. An online library of relevant key articles and reports was initially set up by the module tutor, but this was incrementally developed by the PBL group members themselves as the module progressed, and they discovered further rich resources which deserved sharing with their peers. As most scientists and philosophers are agreed, the facts we find in 'the field' never 
speak for themselves but are impregnated by our assumptions (Silverman, 2001, p. 1). Discussions of subjectivity seem to evoke objectivity as its companion term. To speak objectively implies the speaker is not subjectively colouring their words with feelings, prejudices, values. There is an aura of neutrality. Indeed, objectivity is saturated with the authority of science and professionality, connoting a specialised way of doing things to arrive at the 'facts', a picture of 'reality' and of 'truth' (Schostak, 2002, p. 63).

Stories told in research interviews are rarely clearly bounded by a beginning and an end, and thus locating them is often a complex interpretive process. In addition, the text is not autonomous of its context. It certainly is a problem if researchers are not being properly trained in interviewing techniques, and they proceed in using qualitative research without fully understanding the context of their research. For example, interviews are conversations in which both participants - teller and listener/questioner develop meaning together, a stance requiring interview practices that give considerable freedom to both. Listeners can clarify uncertainties with followup questions and the answers given continually inform the evolving conversation' (Paget, 1983, p. 78).

Olesen et al, in Bryman \& Burgess (1994, p. 111), believe that there is a need for qualitative researchers in certain contexts to have technical knowledge in order to grasp specific issues and to frame or modify the findings. They name certain realms such as health and illness, police work and laboratory science amongst others. As is true in all qualitative work, the goal of this research was to raise the respondents' comments, whilst respecting the integrity of those comments, to a higher order of abstraction that reflected the patterning seen in the comments. They learnt the enduring necessity to be unremittingly and relentlessly reflexive in analysis. Equally important, they believed, was the capacity to be flexible, to look around the corners and beyond some of their dimensions and conceptions, and not to shy away from mixing analytic styles and modes, being always careful to heed to exactly what they were doing.

Good training in theory, and acquaintance with its latest results, is not identical with being burdened with 'preconceived ideas' (Malinowski, 1922, pp. 8-9, in Hammersley \& Atkinson, 1995, p. 24). Richards \& Richards (cited in Bryman \& Burgess, 1994, p. 170) argue that the main task of qualitative research is always theory construction. Theories are actively constructed, not found, like 'little lizards' under rocks (Miles \& Huberman, 1994).

The relationships between problems, theories and methods within the qualitative investigation can also be problematic: 'The lived always seeks to be represented in some way and thus sacrifices the sense of life for the sense of words and meanings in order to relive' (Schostak, 2002, p. 2). As uncovered by the PBL group, the qualitative interview is a principal research tool for the sociologist, educator, political scientist, criminologist, public administrator, social worker, anthropologist and historian (Rubin \& Rubin, 1995, p. 3). Through what is heard and learnt from qualitative interviews, the researcher 
can extend their intellectual and emotional reach across time, class, race, sex and geographical divisions. However, Riessman (1993, p. 3) argues, in research interviews, respondents will hold the floor for lengthy turns and sometimes organise replies into long stories. Traditional approaches to qualitative analysis often fracture these texts in the service of interpretation and generalisation by taking bits and pieces, snippets of a response edited out of context, which can arguably be likened to what happens in journalism.

Negatively, the information collected from interviews may be clouded by the problem of recall. A series of interpretive decisions confronts all qualitative researchers. They must consider how to facilitate narrative telling in interviews, transcribe for the purposes at hand, and approach narratives analytically. Reissman (1993, p. 56) states that provided qualitative researchers can give up control over the research process and approach interviews as conversations, almost any questions can generate a narrative.

Qualitative research is not looking for principles that are true all the time and in all conditions. Knowledge in qualitative interviewing is situational and conditional. Rubin \& Rubin (1995, p. 257), in their text, outline guidelines for including qualitative information into a report that is convincing, thoughtprovoking, absorbing, vivid and fresh.

Weatherburn et al's (1992) research was part of Project SIGMA, and their use of the interview highlights the advantages of qualitative research in offering an apparently 'deeper' picture than the variable-based correlations of quantitative studies (Silverman, 2001, p. 18).

\section{What is Important in Qualitative Research?}

The aim of this aspect of the article is to set out a coherent argument formed by the PBL group, with the relevant evidence for stating that qualitative research does offer something useful to the research community, and it helps researchers ask interesting questions. In particular, the group was required to explore the PBL problem it had been set: using interviews to establish the equal participation of students from ethnic minorities in higher education.

Up until this juncture, the areas within qualitative research which have been contentious for the PBL group have been outlined. Figure 1 summarises the fruits of this discussion as a continuum within qualitative research, and provides the link between the negative and positive aspects of the approach.

As has been established, there is an argument about flexibility within the approach; for some, this flexibility encourages qualitative researchers to be innovative; for others, it might be criticised as meaning lack of structure. There are certain claimed features of qualitative methods: soft, flexible, subjective, political, case study, speculative, grounded (Halfpenny, 1979, p. 799). Qualitative research seeks its data from the ways in which realities are framed and potentially reframed. The way in which the qualitative researcher frames the research problem and their openness in reframing it, if necessary, is important. 


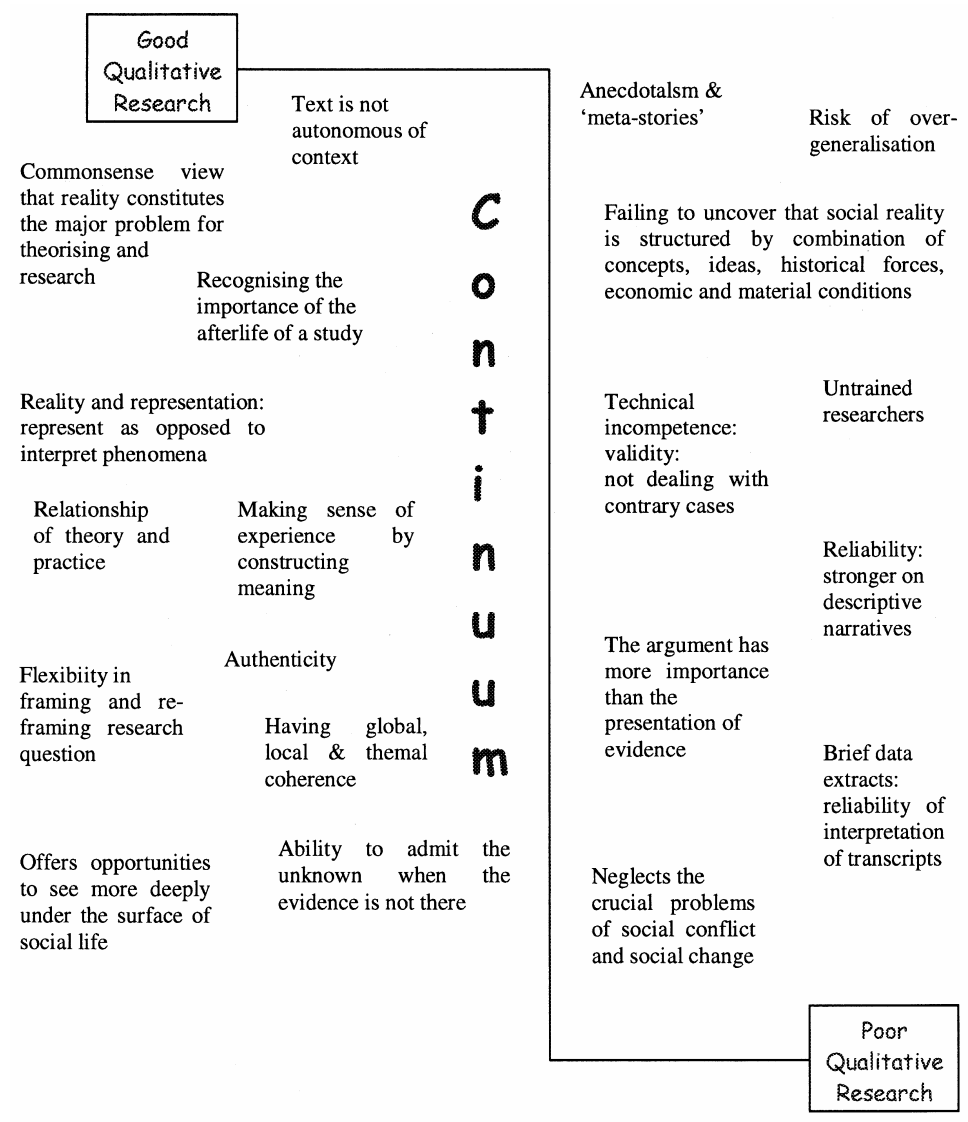

Figure 1. The continuum between good and poor practice in qualitative research interviews.

The audience is also important, and can be looking for different things from reading the research, so language is an aspect to be considered. For example, the language of research reports is often impenetrable for participants and practitioners. It is essential for social scientists to communicate with a wide audience if their evidence is to be taken into account. If the language used in the qualitative interview is not clear, the research results will only reach a limited audience (Burgess, 2000, p. 216). The wider audience in the instance of this problem can include policy-makers, practitioners and the general public in a European context. Each group will only want to hear about qualitative research if it relates to their needs. The research can be sensitive to debates, circumstances, ethics and politics. Qualitative researchers need to decide if they are satisfied simply with keeping their audience sufficiently interested that they will want to turn the page. Is qualitative research any different from good journalism? Should they want to achieve anything more? 
Whenever there is a commitment to particular policies and politics, there is a temptation for academic researchers to move beyond the data. However, in spite of these doubts about the potential influence of academic research, without objectivity as a goal, social research becomes indistinguishable from journalism or political polemic (Walford, 2001, p. 133).

It is also important for the qualitative researcher to say 'I don't know' when the evidence is not there. The posture of 'not knowing' is a hallmark of qualitative inquiries. Chenail $(1997$, p. 2) believes it is the wonderful strength of these approaches to research and practice. Yet it also can become a grave weakness if researchers fail to understand how they go about 'not knowing' or, said in more positive terms, researchers have to know how they go about not knowing.

\section{Good Qualitative Practice}

A suggestion for tactics for this problem was to avoid personal involvement with subjects as friends. Ethical and practical problems such as over-rapport suggest reasons for this rule (Easterday et al, in Burgess, 1982, p. 66). Generally, problems include researcher bias, data distortion and limitation, reactivity; these can be particularly noticeable in dealing with sensitive issues such as ethnic minorities. An example of good practice in this area by this team of qualitative researchers was to equalise time with all people in the interview situation, by not discussing details of the research with the informant/friend, and being clear on roles. It is a fortiori impossible to play the role of stranger and friend at the same time in integrity while trying to combine them, with the result that an uneasy compromise is liable to be forged (Jarvie, in Burgess, 1982, p. 68).

Agreeing with Reissman (1993) and Blackman (1992), Reason \& Rowan (1981) (cited in Silverman, 2001, p. 235) put forward as good research that which goes back to the subjects with tentative results, and refines them in the light of the subjects' reactions.

\section{The Value of Qualitative Research}

Finally, in this article, I wish to move towards conclusion by continuing the PBL group's argument for qualitative research interviews having a distinctive value in the investigation of the PBL problem: establishing the equal participation of students from ethnic minorities in higher education, in a European context.

Mason (1996, p. 171) believes that at each point in the research process, qualitative research practitioners will be asking 'why?', 'how?', 'what are the consequences?' and through this self-interrogation will produce qualitative research which is intellectually sophisticated, ethically and politically acceptable, practically feasible, socially relevant, as well as enjoyable and stimulating for those at all levels in creating and consuming it. Based on this, it 
is fair to say that qualitative research approaches in interviews are only as good as the questions they set out to illuminate. Similarly, Backett-Milburn (1999, p. 69) advocates that care must be taken to promote ways of doing, evaluating and assessing qualitative research interviews which are appropriate to its epistemological roots.

A consensus has yet to be reached to determine the exact qualitative research boundaries and the main components of a researcher through this methodological maze. For some researchers, such ambiguity can constitute a source of anxiety, as we have seen earlier. However, some others will view it as an opportunity for innovation, that is, a chance to 'break the mould' and conceive a research strategy that will meet the researcher's specific needs and objectives (Audet $\&$ d'Amboise 2001, p. 1).

Each research project then, is vital in the search for ways to enhance freedom, creativity and the quality of life. Qualitative research interviews, with their detailed focus on the complexities of social interaction, the collection of data and its interpretation, have a powerful role to play (Schostak, 2002, p. 232).

\section{Conclusion}

The PBL group decided it was also appropriate to put forward as the outcome of their problem deliberations a set of 'reminders' on the potential of the qualitative research interview in this European context of investigating the equal participation of students from ethnic minorities in higher education: taking advantage of naturally occurring data, avoid treating the actor's point of view as an explanation, study the interrelationships between elements, attempt theoretically fertile research, address wider audiences, begin with 'how?' questions, followed by 'why?', being aware that phenomena can take on different meanings in different contexts.

Overall, there appears to be no canonical approach in general qualitative work, no recipes and formulas, and different validation procedures may be better suited to some research problems than to others. The PBL group decided that their ultimate goals are to learn about substance, make theoretical claims through method, and learn about the general from the particular. Any methodological standpoint is, by definition, partial, incomplete, and historically contingent. Diversity of representations is needed.

However, at the end of the 10-week module, the PBL group concluded that the challenge for qualitative researchers in this new millennium is to articulate as fully as possible the processes associated with its data analysis of interviews. Page (2000, p. 2) concurs generally but goes further by stating that in a transforming world, the future of qualitative methodology may lie less in whether it can be satisfactorily standardised or made more rigorously scientific and more in whether a professional community can re-establish stewardship amid the diffuse array of genres now laying claim to the label qualitative research. 
PBL in this module provided a meaningful experience aimed at the participants applying knowledge and real-world applications toward the improvement of their performance. On evaluation of the module, there was no doubt that along with the valuable learning that took place in the area of qualitative research, the approach of PBL that was used to achieve this did present a number of challenges for both students and the tutor. Time is always a factor in this approach to learning. Ten weeks was considered too short a duration in which to fully explore all the learning issues associated with the problem. The participants would have preferred more time to digest, comprehend and integrate the materials they uncovered. Initially also, there was some role anxiety from the participants as part of working collaboratively on the problem, but as their confidence grew, this was overcome. Assessment can be a sensitive issue in PBL (Biggs, 1999) due to the fact that it is an essentially divergent or open-end mode of teaching that is not aligned to the more common convergent formats of assessment. However, by giving the participants the assessment criteria for the module in advance, and explaining the constructive alignment in the curriculum between the module objectives, learning approach and assessment strategy used, this was also surmounted.

Therefore, the transition to working in this way was initially not only difficult for tutors, it was also a big change for the module participants. PBL required more of the participant's time and it was expected that the participants would be responsible and independent learners. The tutors needed to make the transition smooth for students (Bridges, 1992). The continuing success of the module will depend on effective communication and orientation.

\section{References}

Audet, J. \& d'Amboise, G. (2001) The Multi-site Study: an innovative research methodology, The Qualitative Report [Online Serial], 6(2), pp. 1-16.

Backett-Milburn, K. (1999) Plus ça change? Reflections on a Career as a Qualitative Researcher, International Journal of Social Research Methodology, 2, pp. 69-81.

Barrows, H. (1999) Problem-based Learning: a total approach to education. Springfield: Southern Illinois University School of Medicine.

Behar, R. (1993) Translated Woman: crossing the border with Esperanza's story. Boston: Beacon.

Biggs, J. (1999) Teaching for Quality Learning at University. Buckingham: Society for Research into Higher Education.

Blackman (1992) FULL REF NEEDED PLEASE

Bridges, E.M. (1992) Problem Based Learning for Administrators. Eugene: ERIC Clearinghouse on Educational Management (ERIC Document Reproduction Service No. ED 347 617).

Bryman, A. \& Burgess, G. (Eds) (1994) Analysing Qualitative Data. London: Routledge. 
Burgess, R.G. (1982) Field Research: a sourcebook and field manual. London: Allen \& Unwin.

Burgess, R.G. (2000) In the Field: an introduction to field research. London: Routledge.

Chenail, R. (1997) Keeping Things Plumb in Qualitative Research, The Qualitative Report [Online Serial], 3(3), pp. 1-7.

Cicourel (1964) FULL REF NEEDED PLEASE

Connell et al (2001) FULL REF NEEDED PLEASE

Denzin, N. \& Lincoln, Y. (Eds) (2000 1994 IN TEXT) Handbook of Qualitative Research. Thousand Oaks: Sage.

Gubrium, J. \& Holstein, J. (1997) The New Language of Qualitative Method. New York: Oxford University Press.

Halfpenny, P. (1979) The Analysis of Qualitative Data, Sociological Review, 27, pp. 799-825.

Hammersley, M. \& Atkinson, P. (1995) Ethnography, Principles in Practice, 2nd edn. London: Routledge.

Marshall \& Rossman (1999) FULL REF NEEDED PLEASE

Mason, J. (1996) Qualitative Researching. London: Sage.

Miles \& Huberman (1994) FULL REF NEEDED PLEASE

Page, R.N. (2000) Future Directions in Qualitative Research, Harvard Educational Review, 70, pp. 100-108.

Paget, M.A. (1983) Experience and Knowledge, Human Studies, 6, pp. 67-90.

Patton, M.Q. (1990) Qualitative Evaluation and Research Methods, 2nd edn. Newbury Park: Sage.

Peller, G. (1987) Reason and the Mob: the politics of representation, Tikkun, 2(3), pp. 28-95.

Riessman (1993) FULL REF NEEDED PLEASE

Rubin, H. \& Rubin, I. (1995) Qualitative Interviewing: the art of hearing data. London: Sage.

Schostak, J.F. (2002) Understanding, Designing and Conducting Qualitative Research in Education: framing the project. Buckingham: Open University Press.

Selltiz, C., Jahoda, M., Deutsch, M. \& Cook, S. (1964) Research Methods in Social Relations. New York: Holt, Rinehart \& Winston.

Silverman, D. (2001) Interpreting Qualitative Data: methods for analysing talk, text and interaction, 2nd edn. London, Sage.

Singleton, R., Straits, B., Straits, M. \& McAllister, R. (1988) Approaches to Social Research. Oxford: Oxford University Press.

Smeyers, P. \& Verhesschen, P. (2001) Narrative Analysis as Philosophical Research: bridging the gap between the empirical and the conceptual, International Journal of Qualitative Studies in Education, 14, pp. 71-84.

Strauss \& Corbin (1998) FULL REF NEEDED PLEASE 
Walford, G. (2001) Doing Qualitative Educational Research. London: Continuum.

Weatherburn et al (1992) FULL REF NEEDED PLEASE

ROISIN DONNELLY works in the Learning and Teaching Centre in the Dublin Institute of Technology, in the design and delivery of the Postgraduate Certificate, Diploma and Master's in Third Level Learning and Teaching for lecturers. She is currently completing a doctorate in Education (EdD) at Queens University Belfast. Correspondence: Roisin Donnelly, Learning and Teaching Centre, Dublin Institute of Technology, 14 Upper Mount Street, Dublin 2, Ireland ( roisin.donnelly@dit.ie). 